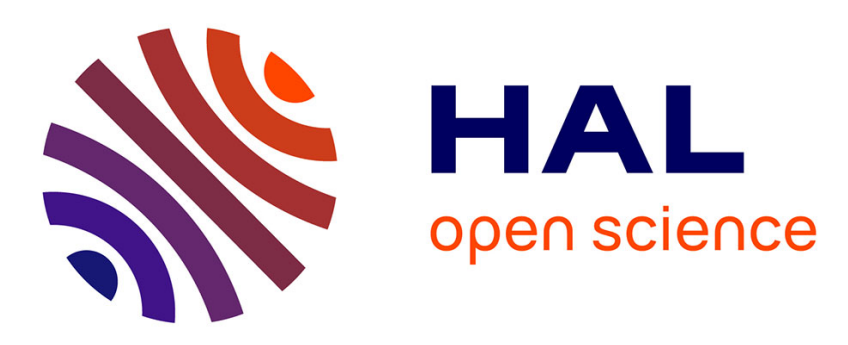

\title{
1-Carbazolyl Spirobifluorene Synthesis, Structural, Electrochemical, and Photophysical Properties
}

Lambert Sicard, Cassandre Quinton, Fabien Lucas, Olivier Jeannin, Joelle

Rault-Berthelot, Cyril Poriel

\section{- To cite this version:}

Lambert Sicard, Cassandre Quinton, Fabien Lucas, Olivier Jeannin, Joelle Rault-Berthelot, et al.. 1-Carbazolyl Spirobifluorene Synthesis, Structural, Electrochemical, and Photophysical Properties. Journal of Physical Chemistry C, 2019, 123 (31), pp.19094-19104. 10.1021/acs.jpcc.9b02507 . hal02278422

HAL Id: hal-02278422

https://hal-univ-rennes1.archives-ouvertes.fr/hal-02278422

Submitted on 14 Oct 2019

HAL is a multi-disciplinary open access archive for the deposit and dissemination of scientific research documents, whether they are published or not. The documents may come from teaching and research institutions in France or abroad, or from public or private research centers.
L'archive ouverte pluridisciplinaire HAL, est destinée au dépôt et à la diffusion de documents scientifiques de niveau recherche, publiés ou non, émanant des établissements d'enseignement et de recherche français ou étrangers, des laboratoires publics ou privés. 


\title{
1-Carbazolyl Spirobifluorene: Synthesis, Structural, Electrochemical and Photophysical Properties
}

\author{
Lambert Sicard, Cassandre Quinton, Fabien Lucas, Olivier Jeannin, Joëlle Rault-Berthelot, and \\ Cyril Poriel* \\ Univ Rennes, CNRS, ISCR-UMR 6226, F-35000 Rennes, France
}

\begin{abstract}
The present work reports one of the rare examples of a new emerging family of spirobifluorene derivatives, namely 1-substituted spirobifluorenes. We report the synthesis and the structural, electrochemical and photophysical properties of 9-(9,9'-spirobi[fluorene]-1-yl)-9H-carbazole 1Cbz-SBF, constructed from the connection of the widely known electron-rich carbazole fragment at the $\mathrm{C} 1$ position of spirobifluorene. We show with 1-Cbz-SBF that the substitution at $\mathrm{C} 1$ induces two important characteristics which drive the electronic properties. First, there is a complete $\pi$ conjugation breaking between the pending substituent, herein carbazole, and the substituted fluorene. Second, there is a through space interaction between the carbazole and its cofacial fluorene. Thanks to a structure-property relationship approach with its constituting building blocks 9,9'-spirobifluorene SBF and carbazole Cbz, we show how some electronic properties are driven by the carbazole unit such as the HOMO energy level whereas others are driven by the fluorene such as the triplet state energy level. As 1-substituted spirobifluorenyl represents a new and promising molecular scaffold for PhOLED applications and more generally for organic electronics, such study provides fundamental knowledge to design future organic materials for specific applications.
\end{abstract}

\section{Introduction}

9,9'-Spirobifluorene (SBF) is one of the most important building block used in the synthesis of Organic Semi-Conductors (OSCs) for Organic Electronics (OE).$^{1-5}$ In recent years, manipulating the substitution pattern of SBF has appeared as a very efficient tool to tune the electronic properties of SBF-based materials. ${ }^{1-2,6}$ In the SBF fragment, there are four positions available for the substitution of each phenyl units numbered 1 to 4 (Chart 1a). This substitution pattern drives the electronic properties of SBF compounds. The position C2 forms a para-substituted biphenyl and has significantly contributed to the development of highly efficient SBF-based materials for OE (chart 1b), mainly as emitters in blue Organic Light-Emitting Diodes (OLEDs) ${ }^{3,5,7-12}$ but also as electron $^{13}$ or hole ${ }^{14}$ transporters in OLEDs and even more recently as very efficient threedimensional non-fullerene acceptors in organic solar cells. ${ }^{15-19}$ The three other positions of the SBF fragment have been far less described to date but appear nevertheless highly promising to build new OSCs. ${ }^{1,20-22}$ The first examples of SBF-based materials substituted at C4 (ortho-substituted biphenyl) ${ }^{21}$ and at C3 (meta-substituted biphenyl) ${ }^{22}$ have only been described in the last ten years, in 2009 and 2013 respectively. The substitution at C1 (meta biphenyl linkage) has only been 
reported in $2017 .{ }^{1}$ However, and oppositely to the substitution at $\mathrm{C} 2$, the particularity of the substitution at $\mathrm{C} 1, \mathrm{C} 3$ or $\mathrm{C} 4$ is the restriction of the electronic coupling between the fluorene unit and the attached substituent. This key characteristic has been advantageously used to design high triplet energy materials $\left(\mathrm{E}_{\mathrm{T}}>2.7 \mathrm{eV}\right)$, which are particularly attractive for hosting phosphors in Phosphorescent OLED (PhOLEDs). ${ }^{2,20}$ Thanks to the combination of a strong steric hindrance and an electronic decoupling, 1-substituted SBF scaffold seems to be the most efficient regioisomer to construct high $\mathrm{E}_{\mathrm{T}}$ materials (for example, 1-Ph-SBF (chart 1c) possesses an $\mathrm{E}_{\mathrm{T}}$ of $2.86 \mathrm{eV}$ ). ${ }^{1}$

On the other hand, it is widely known when designing OSCs for organic electronics that the incorporation of electron-withdrawing and/or electron donating units is an efficient strategy to modulate electronic properties with the aim of reaching high-performance devices. However, it has been shown that the impact of these electron-rich (-poor) functional units is very different as

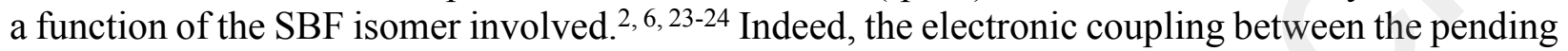
substituent and the fluorene unit depends on the SBF substitution pattern and the resulting steric hindrance and/or nature of the linkage (ortho, meta, para). For example, it has been shown that the modulation of HOMO and LUMO energy levels is very different for 2- and 4-substituted SBFs. ${ }^{18,19}$ Thus, in order to increase the molecular diversity of the emerging family of 1 -substituted SBFs and to apprehend its electronic properties, we report herein the first example of a 1substituted SBF incorporating an electron-rich fragment, namely the widely known carbazole unit. The present work reports a detailed structure-property relationship study of 1-carbazolylspirobifluorene (1-Cbz-SBF) in regard of its constituting building blocks (Spirobifluorene, SBF, and carbazole, $\mathbf{C b z}$ ) and structurally related analogues (1-phenyl-spirobifluorene, 1-Ph-SBF, 1carbazolyl-fluorene, 1-Cbz-F and N-phenyl carbazole N-Ph-Cbz). We show how some electronic properties are driven by the carbazole unit such as the HOMO energy level whereas others such as the triplet state energy level $\mathrm{E}_{\mathrm{T}}$ are driven by the fluorene. This feature provides an interesting degree of tuning for this family of OSCs.

\section{Experimental section}

Experimental section, synthetic procedures and compounds characterization, structural/electrochemical/photophysical properties, computational details and NMR studies are provided in the Supporting Information. 
Chart 1. a) Model compounds used in this study and numbering of the substitution position on one phenyl of the SBF unit, b) Examples of SBF positional isomers incorporating electron rich fragments: 2-substituted SBFs, ${ }^{25-28}$ 3-substituted $\mathrm{SBFs}{ }^{29-30}$ and 4-substituted SBFs. ${ }^{6},{ }^{26-27}$ c) 1 substituted SBFs: 1-Cbz-SBF and 1-Ph-SBF ${ }^{1}$
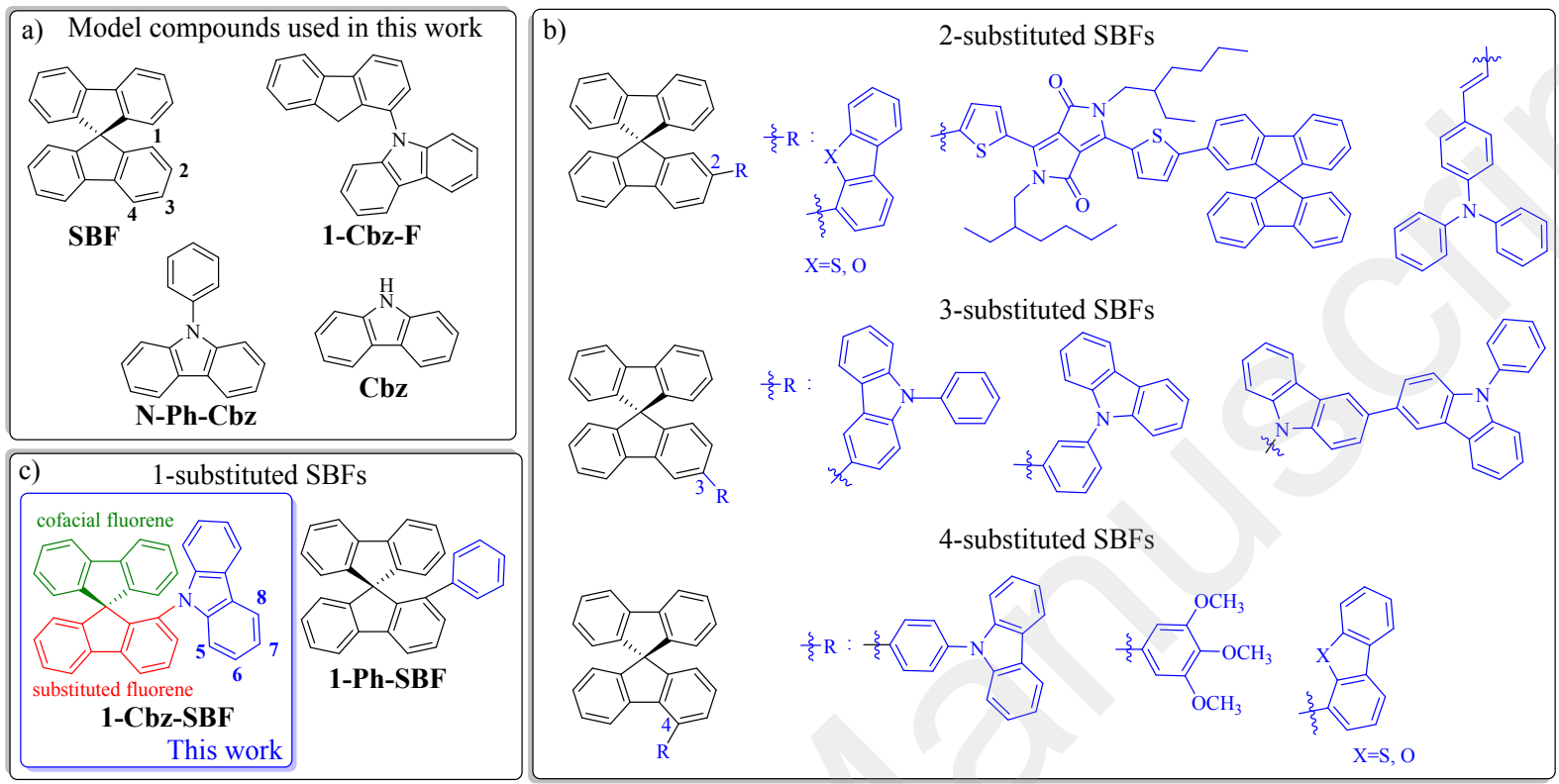

\section{Results and discussions}

Synthesis. Despite initially developed in $1951,{ }^{31} 1$-halogeno-fluorenones have encountered in the last years intense synthetic investigations. ${ }^{1,32-34}$ These key compounds can be advantageously used in the synthesis of 1 -substituted-SBFs as recently shown with 1-Ph-SBF ${ }^{1}$ In this previous work, a synthetic approach towards 1-iodofluorenone was reported, which has nevertheless the disadvantage of being non-regioselective, also providing 3-iodofluorenone. In the present work, the regioselective one-pot approach towards 1-bromofluorenone 1, introduced in 2017 by Sorensen and coworkers, ${ }^{33}$ has been used (Scheme 1). This reaction is a $\mathrm{Pd}(\mathrm{II})$-catalysed $\mathrm{C}\left(\mathrm{sp}^{2}\right)$ functionalization cascade starting from iodobenzene and 2-bromobenzaldehyde. This one pot approach is not only regioselective but also quick and easy to perform, which should allow to deeply develop 1-fluorenones and consequently 1-substituted SBFs in the future. With $\mathbf{1}$ in hand, the carbazole fragment was then attached via a copper-catalysed Goldberg reaction $\left(\mathrm{CuO} / \mathrm{TMEDA} / \mathrm{K}_{3} \mathrm{PO}_{4}, 180^{\circ} \mathrm{C}\right)$ to provide the corresponding 1-carbazolyl-fluorenone 2 with a high yield of $95 \%$. The synthesis of 1-Cbz-SBF was then carried out through a classical two-step procedure: lithium-iodine exchange of 2-iodobiphenyl with $n$-butyllithium at low temperature, followed by trapping of the lithiated intermediate with fluorenone $\mathbf{2}$. The resulting fluorenol $\mathbf{3}$ (not isolated) is finally involved in an intramolecular aromatic electrophilic substitution $(\mathrm{AcOH} / \mathrm{HCl})$ to provide the 1-carbazolyl-spirobifluorene 1-Cbz-SBF with a yield of $68 \%$ over the two steps. We should mention that, despite a sterically hindered environment, the $\mathrm{C} 1$ position allows to incorporate substituents and even a spirolinked fluorene with good yields. Note that 1-carbazolylfluorenone $\mathbf{2}$ can be a useful synthetic intermediate to further introduce other spirolinked fragments of interest for OE such as phenylacridine, ${ }^{35}$ xanthene, ${ }^{36}$ or quinolinophenothiazine. ${ }^{37}$ 
Scheme 1. Synthesis of 1-carbazolyl-spirobifluorene 1-Cbz-SBF

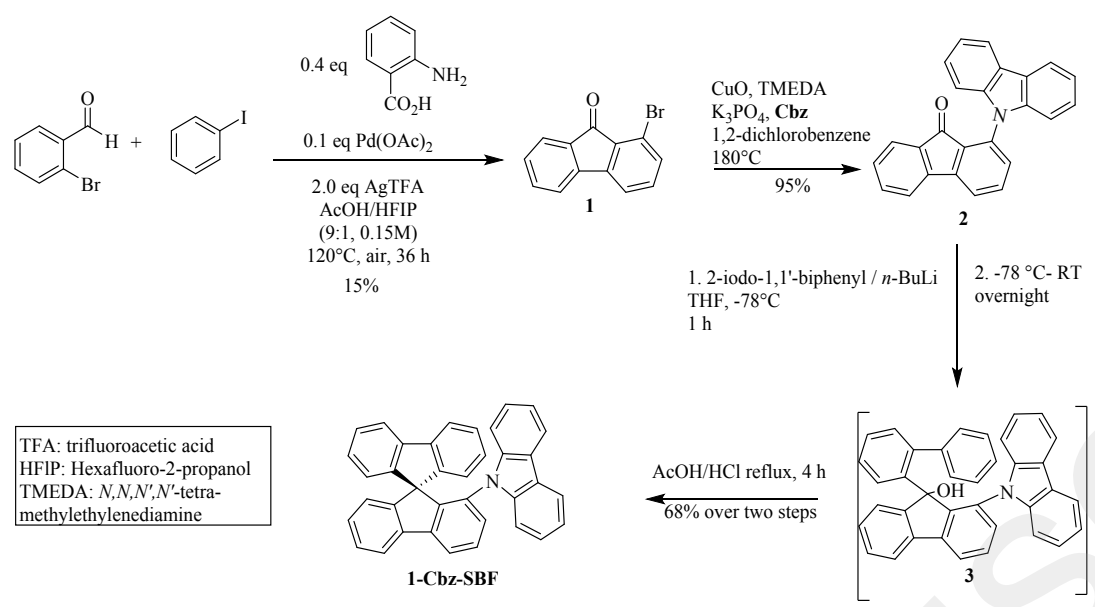

An important and characteristic in 1-substituted SBFs is the particular face to face arrangement of the pending substituent (colored in blue in chart 1c) and the non-substituted cofacial fluorene (colored in green in chart 1c). Such an arrangement appears unique in the SBF family and the possible interactions between these two fragments have therefore never been studied to date. In order to determine the impact of this cofacial arrangement on the hydrogen atoms resonances, complete ${ }^{1} \mathrm{H}$ NMR assignations were performed by 2D NMR spectroscopy for 1-Cbz-SBF and compared to relevant model compounds SBF, 1-Ph-SBF and Cbz (Figure 1). All the chemical shifts are gathered in Table S1. 
In the model compound SBF, the chemical shifts of $\mathrm{H} 1-\mathrm{H} 4$ are respectively detected at 6.68, 7.13, 7.39 and $7.89 \mathrm{ppm}$ (Figure 1). ${ }^{38}$ In 1-Ph-SBF, H1 is detected at $6.70 \mathrm{ppm}$, at an almost identical chemical shift than that of SBF $(\delta=6.68 \mathrm{ppm}$, Table S1), this proton being therefore not influenced by the cofacial phenyl. On the other hand, H4 is significantly shielded by ca 0.5 ppm in 1-Ph-SBF compared to its homologue in SBF (7.40 vs $7.89 \mathrm{ppm}$, Figure 1). One can note that the chemical shift difference between the fluorene hydrogen atoms of SBF and those of 1-Ph-SBF gradually increases from $\mathrm{H} 1$ to $\mathrm{H} 4$. This shielding effect may be assigned to the increased overlap of the two face-to-face aromatic rings of 1-Ph-SBF. Indeed, transannular $\pi-\pi$ interactions are usually accompanied by high field shifts in ${ }^{1} \mathrm{H}$ NMR spectra and have been observed in many different $\pi$-systems such as fluorene, ${ }^{39-41}$ paracyclophane, ${ }^{42}$ thiophene, ${ }^{43}$ pyrenes, ${ }^{44}$ and dihydroindeno[2,1a]fluorene. 5, 38, 41, 45 In the present 1-Cbz-SBF, the shielding effect is even accentuated compared to 1-Ph-SBF. Indeed, H1-H4 are respectively detected at 6.65, 6.79, 6.90 and $6.80 \mathrm{ppm}$, the latter being impressively shielded by more than $1 \mathrm{ppm}$ compared to $\mathbf{S B F}$ ( $\delta=7.89 \mathrm{ppm}$ ). Thus, due to the inclination of the carbazole unit (see X-ray structure in Figure 2), H4 is the most influenced by the anisotropy cone and hence the most shielded. As a function of the substituent grafted at $\mathrm{C} 1$, the chemical shifts of the cofacial fluorene (and hence the strength of the $\pi-\pi$ interactions) can be therefore modulated. This is an interesting characteristic of 1-substituted SBFs. The hydrogen atoms of the carbazole unit are also strongly affected by the cofacial arrangement. Indeed, the comparison of the chemical shifts of the hydrogen atoms of the carbazole unit in 1-Cbz-SBF and in $\mathbf{C b z}$ clearly leads to the same conclusions. Thus, hydrogen atoms $\mathrm{H} 5-\mathrm{H} 8$ in $\mathbf{C b z}$ are respectively 
detected at 7.42, 7.42, 7.21 and 8.06 ppm and at 6.20, 6.83, 6.94 and 7.75 ppm in 1-Cbz-SBF. In this case, the most influenced hydrogen is H5 in accordance with the inclination of the carbazole unit.

Structural properties. Single crystals of $\mathbf{1 - C b z - S B F}$ were grown from $\mathrm{CHCl}_{3} / \mathrm{MeOH}$. The first and evident structural particularity of 1-Cbz-SBF is the cofacial arrangement between the carbazole and the cofacial fluorene. Thanks to the substitution at $\mathrm{C} 1$, one can note a very high dihedral angle of $84.1^{\circ}$ between the mean plane of the substituted fluorene and that of the carbazole. This large dihedral angle is at the origin of the electronic decoupling noticed below in the physico-chemical properties. In addition, one can note that this angle is higher than that reported for 1-Ph-SBF $\left(75.4^{\circ}\right)^{1}$ and highlights the importance of the substituent itself and especially its size on the structural characteristics. As previously shown for 4-substituted SBFs, ${ }^{2}$, 21 this dihedral angle can be therefore used to modulate the electronic coupling between the fluorene and the pending substituent. The molecular structure of 1-Cbz-SBF displays many short intramolecular distances between the two cofacial fragments (Figure 2a and Figures S3-S7). Some $\mathrm{C} / \mathrm{C}$ distances are shorter than the sum of their van der Waals radii $(3.4 \AA)^{46}$ and translate a sterically hindered environment. The shortest distance is measured between the two carbon atoms $\mathrm{C} 1$ of the cofacial fluorene and C5 of the carbazole (3.27 $\AA$ ). In order to precisely evaluate the strength of these interactions between the carbazole and the cofacial fluorene, three structural parameters have been evaluated for the four cofacial phenyl rings, namely ring-centroid/ringcentroid distance $d_{C-C}$, vertical displacements $d_{1}$ and $d_{2}$ and slippage angles $\theta_{1}$ and $\theta_{2}$ (Figure $2 d$ and Figure S1 for definitions and calculation methods). As discussed by Janiak and coworkers, these three parameters can reflect the strength of the interactions between two phenyl rings. ${ }^{47-50}$ In 1-Cbz-SBF, the ring-centroid/ring-centroid distances between two cofacial phenyl rings of the carbazole and fluorene units are estimated at ca. $3.78 \AA$ and $3.84 \AA$ (Figure S2 and Table S2). The smallest vertical displacements between two phenyl rings are very short $(0.65 \AA$ and $0.39 \AA$, Table S2) and their corresponding ring slippage angles are very low $\left(9.9^{\circ}\right.$ and $5.9^{\circ}$, Table $\left.\mathrm{S} 2\right)$. In the light of Janiak's works such values of ring-centroid/ring-centroid distance $(<3.8 \AA)$, vertical displacements $(<1.5 \AA)$, and ring slippage angles $\left(<25^{\circ}\right)$ indicate strong interactions between carbazole and fluorene. 

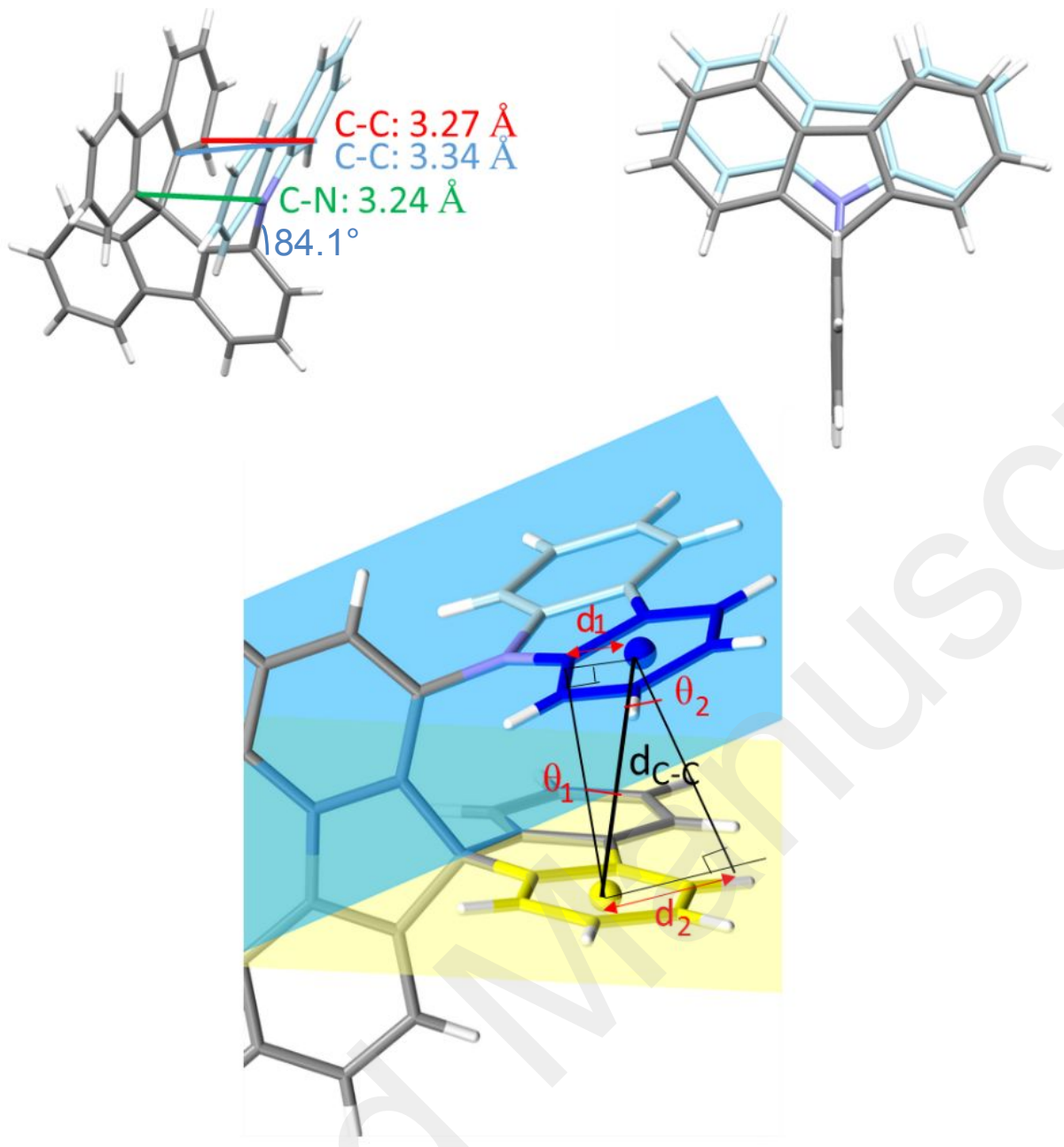

Figure 2. Top) Molecular structure of 1-Cbz-SBF from X-ray diffraction (two different views) Bottom) Representation of the crystallographic parameters to evaluate the strength of $\pi-\pi$ interactions as described by Janiak and coworkers. ${ }^{47-50}$

Electrochemistry. The electrochemical properties of 1-Cbz-SBF have been studied in $\mathrm{CH}_{2} \mathrm{Cl}_{2}+$ $\mathrm{Bu}_{4} \mathrm{NPF}_{6} 0.2 \mathrm{M}$ using cyclic voltammetry $(\mathrm{CV})$ and first compared to those of the two constituting building blocks, Cbz and SBF. 

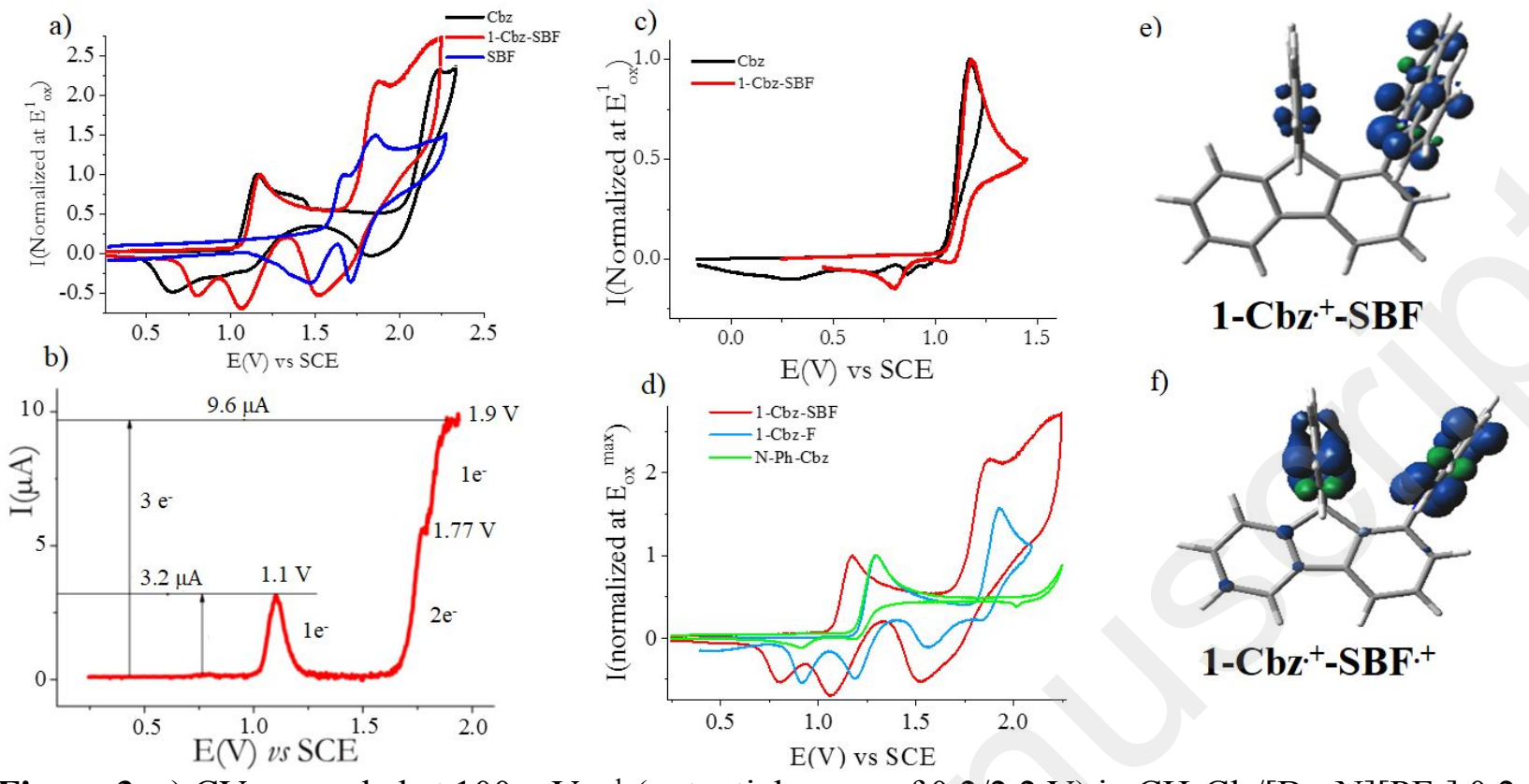

Figure 3. a) $\mathrm{CVs}$ recorded at $100 \mathrm{mV} \mathrm{s}{ }^{-1}$ (potential range of $0.2 / 2.2 \mathrm{~V}$ ) in $\mathrm{CH}_{2} \mathrm{Cl}_{2} /\left[\mathrm{Bu}_{4} \mathrm{~N}\right]\left[\mathrm{PF}_{6}\right] 0.2$ $\mathrm{M}$ in the presence of 1-Cbz-SBF (red line), SBF (blue line), and Cbz (black line). b) Differential pulse voltammetry of 1-Cbz-SBF. c) CVs recorded at $100 \mathrm{mV} \mathrm{s}^{-1}$ (potential range of $-0.2 / 1.45 \mathrm{~V}$ ) in $\mathrm{CH}_{2} \mathrm{Cl}_{2} /\left[\mathrm{Bu}_{4} \mathrm{~N}\right]\left[\mathrm{PF}_{6}\right] 0.2 \mathrm{M}$ in the presence of 1-Cbz-SBF (red line) and $\mathbf{C b z}$ (black line). d) CVs recorded at $100 \mathrm{mV} \mathrm{s}^{-1}$ (potential range of $0.2 / 2.25 \mathrm{~V}$ ) in $\mathrm{CH}_{2} \mathrm{Cl}_{2} /\left[\mathrm{Bu}_{4} \mathrm{~N}\right]\left[\mathrm{PF}_{6}\right] 0.2 \mathrm{M}$ in the presence of 1-Cbz-SBF (red line), N-Ph-Cbz (green line) and 1-Cbz-F (sky blue line). Intensity is normalized at $\mathrm{E}_{\mathrm{ox}}{ }^{1}$ for all the compounds. Spin densities of (e) the cation radical and the bis radical cation (f) of 1-Cbz-SBF (isovalue $=0.004$, cam-b3lyp/6-31g(d)).

In oxidation, 1-Cbz-SBF presents two distinct waves with maxima at 1.17 and $1.87 \mathrm{~V}$ (Figure 3a, red line) followed by an additional oxidation at a potential higher than $2.25 \mathrm{~V}$ (potential limit reached). Thus, the first oxidation of 1-Cbz-SBF occurs at almost identical potential value than that of $\mathbf{C b z}(1.16 \mathrm{~V}$, Figure 3c, black line) translating an electron transfer centered on the carbazole unit. This is in accordance with the HOMO distribution of 1-Cbz-SBF (Figure 7) and of the spin density of its cation-radical (Figure 3e) both localized on the carbazole unit. From the onset potential of the first oxidation wave, 1.07 V, the HOMO energy level of 1-Cbz-SBF is evaluated at $-5.47 \mathrm{eV}$. As HOMO level of 1-Cbz-SBF is distributed on the carbazole unit, its energy is higher than that of SBF (-5.95 eV, HOMO localized on fluorene) and almost identical to that of $\mathbf{C b z}$ $(-5.50 \mathrm{eV})$.

At this stage, it is interesting to compare the oxidation of 1-Cbz-SBF to that of another model compound, N-phenyl-Carbazole (N-Ph-Cbz), ${ }^{6}$ the carbazole having a phenyl group substituting the nitrogen atom (See structure in chart 1a). Thus, as presented Figure 3d (green line), the first oxidation of N-Ph-Cbz is shifted to more anodic values $(1.30 \mathrm{~V})$ compared to that of both 1-CbzSBF and $\mathbf{C b z}(1.17 \mathrm{~V})$, all $\mathrm{CVs}$ being recorded in identical conditions $\left(\mathrm{CH}_{2} \mathrm{Cl}_{2} /\left[\mathrm{Bu}_{4} \mathrm{~N}\right]\left[\mathrm{PF}_{6}\right] 0.2\right.$ M). The potential difference between $\mathbf{C b z}$ and $\mathbf{N}-\mathbf{P h}-\mathbf{C b z}$ can be explained by the negative inductive effect of the phenyl ring which leads to a carbazole unit more difficult to oxidize in $\mathbf{N}$ Ph-Cbz than in Cbz. It is indeed known that the substituent borne by the nitrogen atom has a consequent impact on the first oxidation potential of the carbazole core ${ }^{51}$ For example with a 
For both 1-Cbz-SBF and $\mathbf{C b z}$, the first oxidation is irreversible showing the high reactivity of the charged species (Figure 3c). The weak reduction waves recorded at the reverse scan for both compounds may be assigned to the reduction of a small amount of oligomers precipitated on the electrode surface during the former oxidation. However, as no new oxidation wave appears on the $\mathrm{CV}$ upon successive cycles, one may conclude that these species are soluble in solution in these experimental conditions.

The second oxidation of 1-Cbz-SBF, with its maximum at $1.87 \mathrm{~V}$, appears more difficult to assign with confidence. As shown by the differential pulse voltammetry (Figure 3b), three electrons are involved in this second oxidation process. As this oxidation occurs in the potential range of the two successive oxidation waves of SBF $(1.67 \& 1.86 \mathrm{~V}$, Figure $3 \mathrm{a})$ two of these electron may be therefore ascribed to the oxidation of the SBF unit. This is in agreement with molecular modelling which shows that the electron density of 1-Cbz-SBF bis radical cation is spread out on both cofacial fluorene and carbazole (Figure 3f), indicating that the second oxidation involves the cofacial fluorene leading to $\mathbf{1 - \mathbf { C b z } ^ { + } \mathbf { - S B F }}{ }^{+}$. The following oxidation processes are nevertheless difficult to modelize because of polymerization.

Another interesting feature related to the oxidation of 1-Cbz-SBF is the electrodeposition process observed during recurrent cycles when cycling up to or over the second oxidation potential. It is indeed widely known that SBF derivatives can be polymerized by anodic oxidation leading to 3D materials. ${ }^{56-60}$ However, anodic polymerization of 1-substituted SBFs has never been reported to date. As presented Figure 4-left, one observes the appearance and the regular growth of three new 
redox waves centered at $0.90,1.20$ and $1.60 \mathrm{~V}$ when cycling up to $1.80 \mathrm{~V}$ or at $1.00,1.30$ and 1.80 $\mathrm{V}$ when cycling up to $2.25 \mathrm{~V}$.

Depending on the anodic limit, the intensity of the new waves increases in a different manner. When cycling to $1.80 \mathrm{~V}$, the currents measured after ten cycles are ca 2 to 3 times higher than those measured at the first cycle. However, when cycling to $2.25 \mathrm{~V}$, the three waves increase more intensively (ca 7 times). This feature can be assigned to the number of positions involved in the electrodeposition process (mainly carbazole units in the first case and both carbazole and fluorene units in the second).
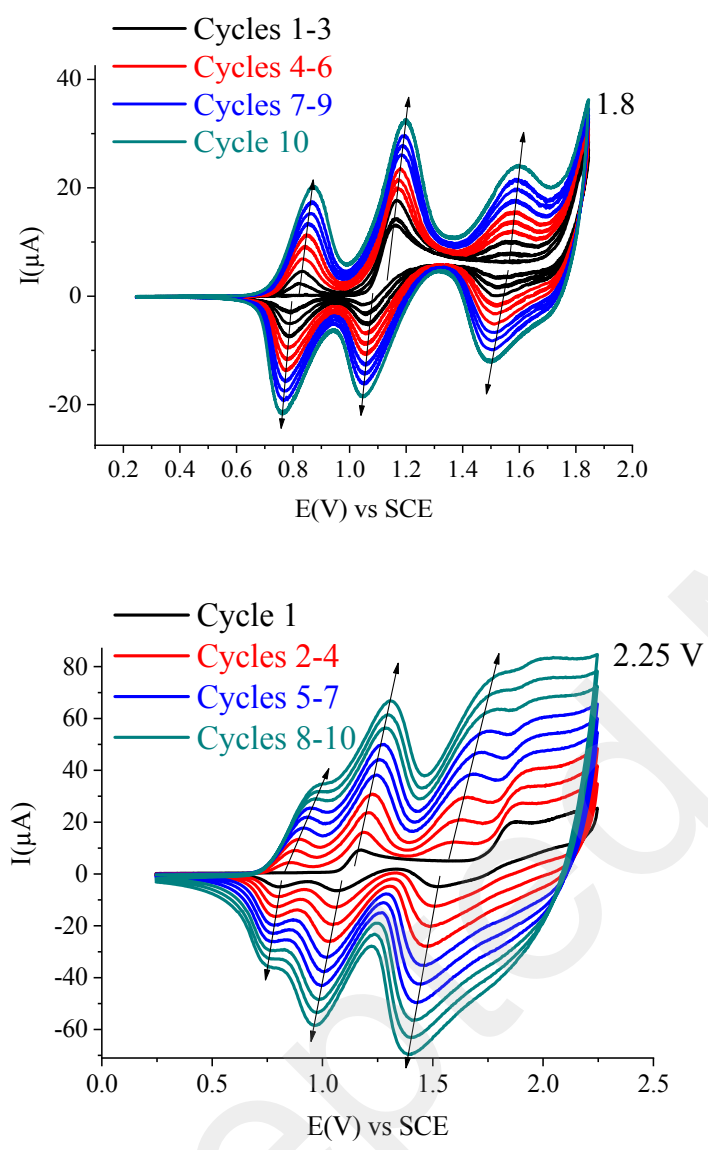
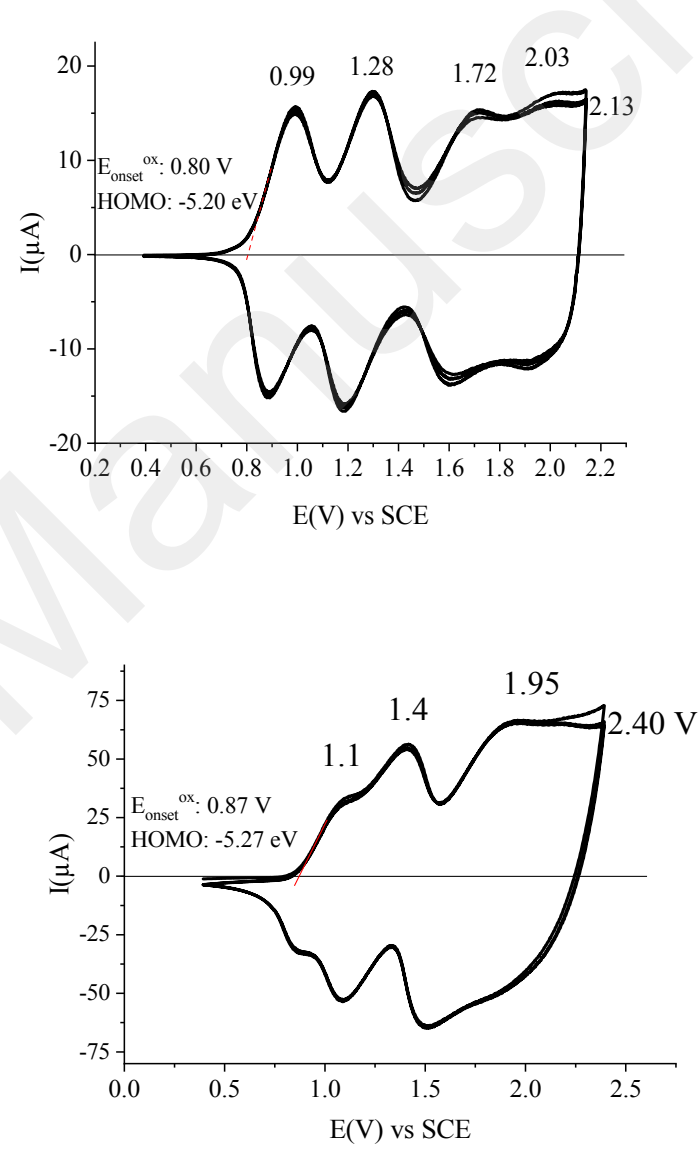

Figure 4. Left: $\mathrm{CV}\left(100 \mathrm{mV} \mathrm{s}^{-1}, \mathrm{CH}_{2} \mathrm{Cl}_{2} /\left[\mathrm{Bu}_{4} \mathrm{~N}\right]\left[\mathrm{PF}_{6}\right] 0.2 \mathrm{M}\right)$ in the presence of 1-Cbz-SBF, 2.7 $10^{-3} \mathrm{M}$, potential range of the ten successive cycles : $0.2-1.8 \mathrm{~V}$ (top) or $0.2-2.25 \mathrm{~V}$ (bottom), platinum disk working electrode. Right: $\mathrm{CV}\left(100 \mathrm{mV} \mathrm{s}{ }^{-1}, \mathrm{CH}_{2} \mathrm{Cl}_{2} /\left[\mathrm{Bu}_{4} \mathrm{~N}\right]\left[\mathrm{PF}_{6}\right] 0.2 \mathrm{M}\right)$ free of any electroactive species, potential limit of the three successive cycles: $0.2-2.13 \mathrm{~V}$ (top) or $0.2-2.40 \mathrm{~V}$ (bottom), platinum disk working electrode modified by the deposits obtained along the ten cycles in presence of 1-Cbz-SBF.

After such oxidations, the electrodes are covered with insoluble deposits. Their electrochemical behaviors (recorded in absence of 1-Cbz-SBF) are presented Figure 4-right. Depending on the potential reached during the electrodeposition, the electrochemical behavior of the corresponding deposits appears somewhat different. When the deposition is performed at low potential (up to $1.80 \mathrm{~V}$ ), the $\mathrm{CV}$ presents four successive redox waves and is stable along recurrent sweeps between 
0.60 and $2.13 \mathrm{~V}$. The corresponding HOMO of the deposit is evaluated at $-5.20 \mathrm{eV}, 0.27 \mathrm{eV}$ higher than that of its corresponding monomer 1-Cbz-SBF. When the deposition is performed at high potential (up to $2.25 \mathrm{~V}$ ), the $\mathrm{CV}$ is less defined (higher currents are nevertheless reached) displaying only three distinct redox waves weakly shifted compared to those of the previously described deposit. One can note that the HOMO of the polymer is slightly lower, ie $-5.27 \mathrm{eV}$, characteristic of a shorter $\pi$-conjugation length. For all the deposits, the range of stability is wide showing a high electrochemical stability between 0.50 and $2.40 \mathrm{~V}$.

The electrochemical behavior of deposits prepared during anodic oxidation is presented Figure 5 and compared to that of Poly $(\mathrm{Cbz})$ and Poly(SBF). The deposit obtained from the oxidation of Cbz possess the highest HOMO ( $\mathrm{E}_{\text {onset }}{ }^{\text {ox }}$ : $0.57 \mathrm{~V}$, HOMO: $-4.97 \mathrm{eV}$ ) whereas that of SBF the lowest $\left(\mathrm{E}_{\text {onset }}{ }^{\text {ox }}: 1.10 \mathrm{~V}\right.$, HOMO: $\left.-5.50 \mathrm{eV}\right)$, translating very different $\pi$-conjugation pathways between the polymers (Figure 5). In between, begins the p-doping process of the deposit derived from 1-Cbz-SBF ( $\mathrm{E}_{\text {onset }}{ }^{\text {ox: }} 0.87 \mathrm{~V}, \mathrm{HOMO}$ : $-5.27 \mathrm{eV}$ ). Such a behavior confirms that carboncarbon couplings leading to the electrodeposition process of $\mathbf{1 - C b z - S B F}$ involve both the carbazolyl and the fluorenyl units. The nature of the deposit is however difficult to precisely determinate because at least six carbon atoms may be involved in bonds formation ( 2 carbon atoms in para positions of the nitrogen atom for carbazole and 2 carbon atoms in para positions of the biphenyl linkage for both fluorenes).

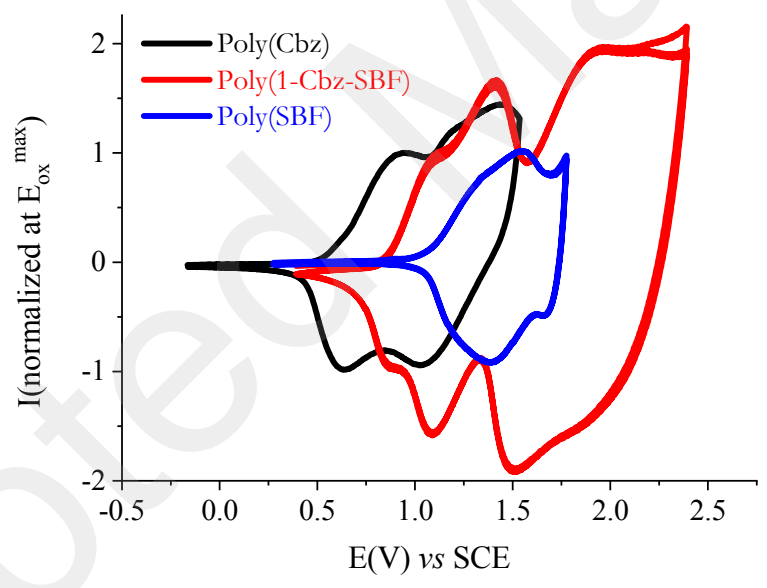

Figure 5. $\mathrm{CV}\left(100 \mathrm{mV} \mathrm{s}^{-1}, \mathrm{CH}_{2} \mathrm{Cl}_{2} /\left[\mathrm{Bu}_{4} \mathrm{~N}\right]\left[\mathrm{PF}_{6}\right] 0.2 \mathrm{M}\right)$ free of any electroactive species, platinum disk working electrode modified by: poly(1-Cbz-SBF) (red line), anodic limit $2.4 \mathrm{~V}$, poly(Cbz) (black line), anodic limit: $2.13 \mathrm{~V}$ or poly(SBF) (blue line), anodic limit $1.76 \mathrm{~V}$. 
Table 1. Selected electronic data of 1-Cbz-SBF, SBF and Cbz

\begin{tabular}{|l|l|l|l|}
\hline & $\mathbf{1 - C b z - S B F}$ & $\mathbf{S B F}^{1}$ & $\mathbf{C b z}$ \\
\hline${\mathrm{HOMO}(\mathrm{eV})^{\mathrm{a}}}^{\mathrm{a}}$ & -5.47 & -5.95 & -5.50 \\
\hline $\begin{array}{l}\text { Potential of } \\
\text { peak oxidation } \\
(\mathrm{V})^{\mathrm{b}}\end{array}$ & $1.17,1.87,2.25$ & $1.67,1.86$ & 1.18 \\
\hline$\lambda_{\text {abs }}(\mathrm{nm})^{\mathrm{c}}$ & $310,323,338$ & 308 & 319,332 \\
\hline$\lambda_{\text {em }}(\mathrm{nm})^{\mathrm{c}}$ & 345,357 & 310,323, & $\begin{array}{l}332,346, \\
361(\mathrm{sh})\end{array}$ \\
\hline$\phi^{\mathrm{c}, \mathrm{d}}$ & 0.39 & $340(\mathrm{sh})$ & 0.25 \\
\hline$\tau(\mathrm{ns})^{\mathrm{c}, \mathrm{e}}$ & 8.1 & 0.40 & 7.7 \\
\hline $\mathrm{k}_{\mathrm{nr}}\left(\mathrm{s}^{-1}\right)^{\mathrm{c}}$ & $7.5 \times 10^{7}$ & 4.6 & $9.7 \times 10^{7}$ \\
\hline $\mathrm{k}_{\mathrm{r}}\left(\mathrm{s}^{-1}\right)^{\mathrm{c}}$ & $4.8 \times 10^{7}$ & $8.7 \times 10^{7}$ & $3.3 \times 10^{7}$ \\
\hline$\lambda_{\mathrm{T}}(\mathrm{nm})^{\mathrm{f}}$ & $438,467,501$ & $431,463,490$, & 406 \\
\hline $\mathrm{E}_{\mathrm{T}}(\mathrm{eV})^{\mathrm{f}}$ & 2.84 & 500 & 3.05 \\
\hline$\tau(\mathrm{s})^{\mathrm{f}}$ & 5.0 & 5.3 & 7.4 \\
\hline
\end{tabular}

a: from electrochemical data, b: vs SCE, c: in cyclohexane, d: referenced to quinine sulfate, e: $\lambda_{\text {exc }}=310 \mathrm{~nm}, \mathrm{f:} 2-\mathrm{MeTHF}$ at $77 \mathrm{~K}$

Optical properties. The UV-vis absorption spectra of 1-Cbz-SBF and of the two building units SBF and Cbz recorded in cyclohexane are presented Figure 6 (left). The absorption spectrum of 1-Cbz-SBF is well structured and displays three main bands at 338,323 and $310 \mathrm{~nm}$. The band at $338 \mathrm{~nm}$ (modelized at $\lambda \mathrm{th}=287 \mathrm{~nm}$, see Figure 7) is red shifted by $6 \mathrm{~nm}$ compared to that of $\mathbf{C b z}$ $(\lambda \exp =332 \mathrm{~nm}$, modelized at $\lambda$ th $=285 \mathrm{~nm})$ and possesses a higher molar absorption coefficient

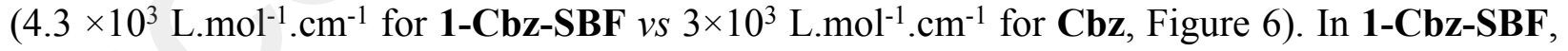
this band is due to a transition involving two contributions: $\mathrm{HOMO} \rightarrow \mathrm{LUMO}+3(56 \%)$ and $\mathrm{HOMO} \rightarrow \mathrm{LUMO}+1(28 \%)$. For the first contribution $(\mathrm{HOMO} \rightarrow \mathrm{LUMO}+3)$, molecular orbitals are both localized on the carbazole and for the second contribution $(\mathrm{HOMO} \rightarrow \mathrm{LUMO}+1)$ the HOMO is spread out on the carbazole whereas the LUMO+1 is located on the cofacial fluorene (Figure 7). The HOMO $\rightarrow$ LUMO transition of $\mathbf{C b z}(\lambda \mathrm{th}=285 \mathrm{~nm})$ involves orbitals with the same shape than the first contribution of the first transition in 1-Cbz-SBF. Therefore, this first contribution can be fully assigned to the carbazole fragment. The second contribution $(\mathrm{HOMO} \rightarrow \mathrm{LUMO}+1)$ involving a through space transfer from carbazole to fluorene can explain both the red shift and the higher molar absorption coefficient of 1-Cbz-SBF compared to Cbz. The second band of 1-Cbz-SBF is 
experimentally found at $324 \mathrm{~nm}(\lambda \mathrm{th}=264 \mathrm{~nm})$ and possesses a molar absorption coefficient of 3.5 $\times 10^{3} \mathrm{~L} \cdot \mathrm{mol}^{-1} \cdot \mathrm{cm}^{-1}$. This band is similar to that found in $\mathbf{C b z}$ at $319 \mathrm{~nm}\left(\varepsilon=3.5 \times 10^{3} \mathrm{~L} \cdot \mathrm{mol}^{-1} \cdot \mathrm{cm}^{-1}\right.$, $\lambda$ th $=264 \mathrm{~nm}$ ) and is mainly due to a $\pi-\pi *$ transition involving orbitals localized on the carbazole fragment (major contributions: HOMO- $\rightarrow$ LUMO +3 for 1-Cbz-SBF and HOMO- $1 \rightarrow$ LUMO for $\mathbf{C b z})$. The third band is experimentally found at $311 \mathrm{~nm}(\lambda \mathrm{th}=271 \mathrm{~nm})$ and possesses a molar absorption coefficient of $1.2 \times 10^{4} \mathrm{~L}_{\mathrm{mol}}{ }^{-1} \cdot \mathrm{cm}^{-1}$. This band, which is also found in $\mathbf{S B F}$ at $308 \mathrm{~nm}$ $\left(\varepsilon=1.4 \times 10^{3} \text { L.mol }{ }^{-1} \cdot \mathrm{cm}^{-1}, \lambda \mathrm{th}=268 \mathrm{~nm}\right)^{1}$ has been assigned to a $\pi-\pi *$ transition having two contributions: HOMO-2 $\rightarrow$ LUMO $(46 \%)$ and HOMO-3 $\rightarrow$ LUMO $(30 \%)$, the three molecular orbitals involved being localized on the SBF fragment. One can indeed note that there is a small red shift of $3 \mathrm{~nm}$ between 1-Cbz-SBF and SBF (which is also found in theoretical calculations: $\lambda=271$ and $268 \mathrm{~nm}$ respectively) which can be assigned to an alteration of the spiroconjugation (conjugation between the two spiro connected fluorenes) ${ }^{61-65}$ probably due to the particular cofacial arrangement.

In the light of TD-DFT analyses, it is finally important to mention that the HOMO $\rightarrow$ LUMO contribution is involved in two transitions $(\lambda \mathrm{th}=272$ and $271 \mathrm{~nm}$ ) having small oscillator strengths (0.0009 and 0.008). Indeed, as exposed in the electrochemical part, the position 1 induces a $\pi$-conjugation breaking between the fluorene and the carbazole leading to the complete spatial separation of HOMO (spread out on the carbazole) and LUMO (spread out on the substituted fluorene). This HOMO $\rightarrow$ LUMO transition is hence strongly disfavored in accordance with a through space electron transfer. ${ }^{35,}$, 66-67 To conclude, the absorption spectrum of 1-Cbz-SBF displays the characteristics of each building block, ie SBF and $\mathbf{C b z}$ but the red shift of the low energy band translates the interactions between the two cofacial units.
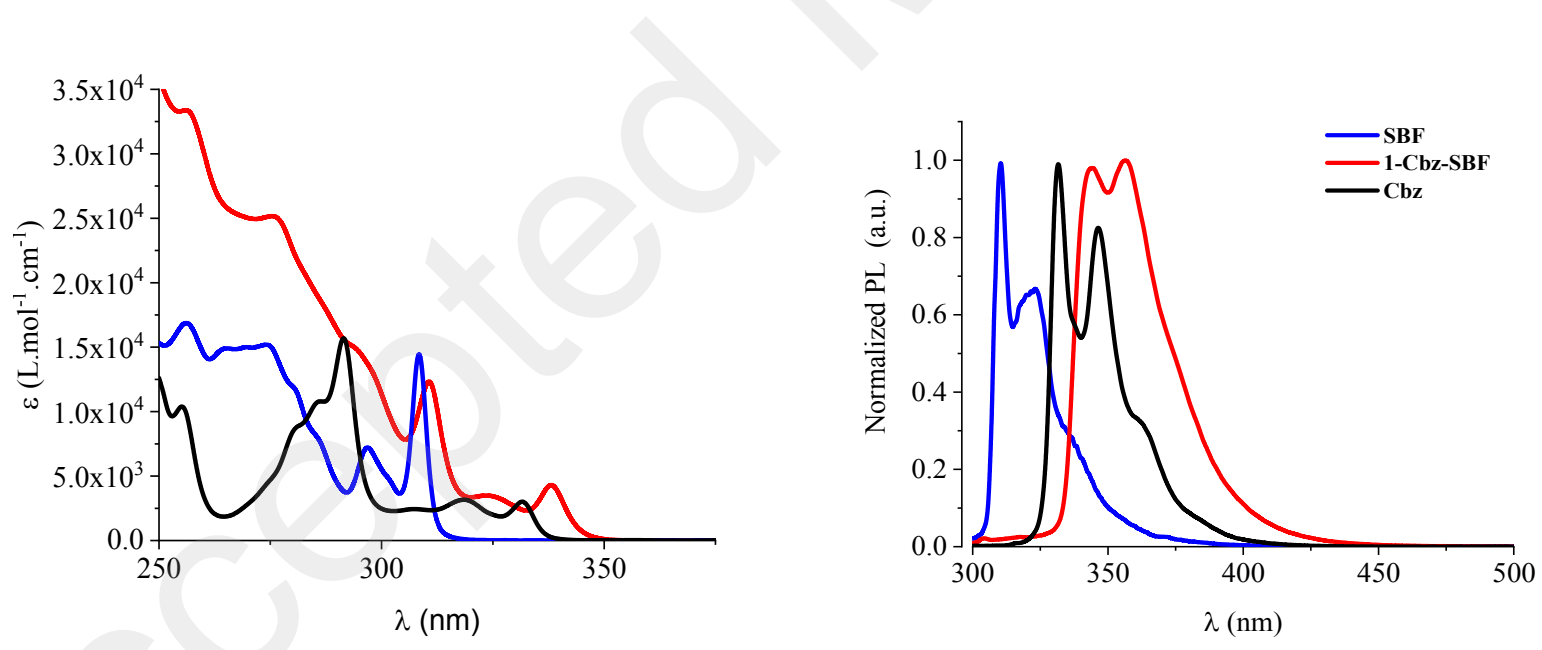

Figure 6. Absorption spectra (left) and normalized emission spectra (right) of 1-Cbz-SBF (red line), SBF (blue line) and $\mathbf{C b z}$ (black line) in cyclohexane at room temperature. 

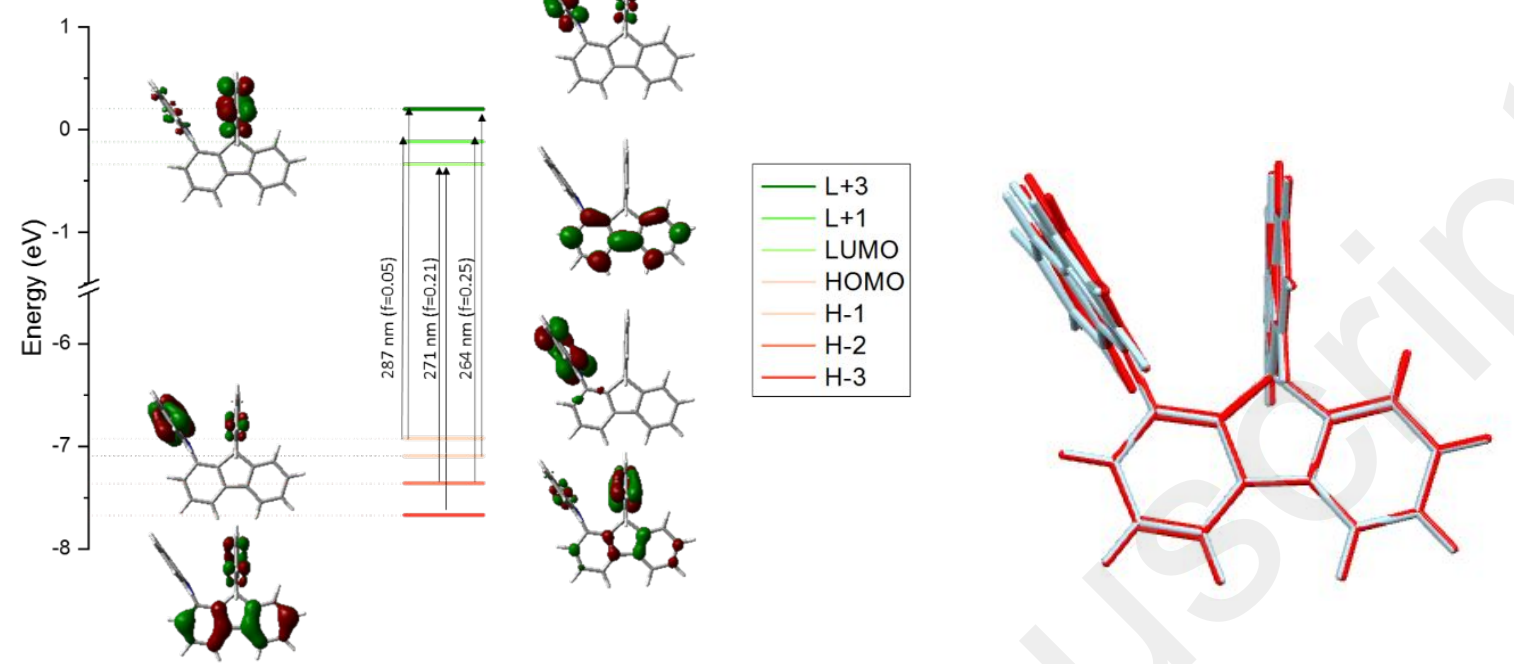

Figure 7. Left: Representation of the energy levels and the main molecular orbitals involved in the electronic transitions of 1-Cbz-SBF obtained by TD-DFT CAM-B3LYP/6-311+G(d,p), shown with an isovalue of 0.04 [e bohr $\left.^{-3}\right]^{1 / 2}$. For clarity purposes, only the major contributions $(>10 \%)$ of each transition is shown (see SI for details). Right: Superposition of optimized geometries of $\mathrm{S}_{0}$ (ground state, light blue) and $\mathrm{S}_{1}$ (first singlet excited state, red).

The fluorescence spectrum of 1-Cbz-SBF presents two maxima at 344 and $357 \mathrm{~nm}$ (Figure 6 right). This violet emission is significantly red shifted compared to both $\mathbf{S B F}$ and $\mathbf{C b z}$ showing the impact of the cofacial arrangement on the emission properties. Thus, despite a $\pi$-conjugation disruption between the carbazole and SBF fragments, the intramolecular interaction of 1-Cbz-SBF induces a red shift of the fluorescence spectrum (as commonly observed when there is an electronic coupling between two $\pi$-systems) compared to its two constituted fragments. The superposition of the optimized geometries of ground state $S_{0}$ and first singlet excited state $S_{1}$ (obtained by TD-DFT b3lyp using 6-31g(d) basis set, see SI) shows that there is only a slight difference between these two states. This allows to conclude that the cofacial arrangement in $\mathbf{1 - C b z - S B F}$ has a key role in its fluorescence, by avoiding strong molecular rearrangements between $\mathrm{S}_{0}$ and $\mathrm{S}_{1}$ (Figure 7-Right). We also suggest that the red shift in fluorescence arises from the cofacial arrangement (and not from a more intense electronic coupling in $\mathrm{S}_{1}$ ) since the angles between the carbazole and the substituted fluorene planes are the same in $\mathrm{S}_{0}$ and $\mathrm{S}_{1}\left(90^{\circ}\right)$. The structured fluorescence spectrum and the small Stokes shift $(7 \mathrm{~nm})$ of 1-Cbz-SBF can also be explained by this very weak reorganization between $\mathrm{S}_{0}$ and $\mathrm{S}_{1}$. This is a different behavior to those previously reported for 2and 4-substituted SBFs but similar to 1-Ph-SBF and therefore a characteristic of 1-substituted SBFs family. ${ }^{6,23}$ The fluorescence decays were successfully fitted by single exponentials (See SI), indicating a unique radiative pathway from $S_{1}$ to $S_{0}$. The lifetime of $\mathbf{1 - C b z - S B F}\left(\lambda_{\text {exc }}=310 \mathrm{~nm}\right.$, Figure S16) is recorded at $8.1 \mathrm{~ns}$, longer than the lifetimes of SBF (4.6 ns) ${ }^{1}$ and $\mathbf{C b z}(7.7 \mathrm{~ns}$, Figure S17), showing once again that the fluorescence of 1-Cbz-SBF is not the superposition of the emission of $\mathbf{C b z}$ and SBF but comes from a single fluorophore. Finally, the quantum yield $\phi$ of 1Cbz-SBF was calculated in solution at 0.39 and is identical to that of SBF $(0.40)^{1}$ and higher than 
the one of $\mathbf{C b z}(0.25)$. As the non-radiative constant of 1-Cbz-SBF $\left(\mathrm{k}_{\mathrm{nr}}=7.5 \times 10^{7} \mathrm{~s}^{-1}\right)$ is smaller than those of the fragments SBF and $\mathbf{C b z}$ (resp. $\mathrm{k}_{\mathrm{nr}}=13.0 \times 10^{7} \mathrm{~s}^{-1}$ and $9.7 \times 10^{7} \mathrm{~s}^{-1}$ ), one can conclude that the internal conversion processes are limited for 1-Cbz-SBF compared to both SBF and $\mathbf{C b z}$.

At this stage, it seems relevant to compare the photophysical data of 1-Cbz-SBF to those of 1-PhSBF in order to analyze the impact of the C1-subsituted SBF scaffold on the photophysical data. The first difference is linked to the quantum yield, which is around $2 / 3$ lower for 1-Cbz-SBF (0.39) than for 1-Ph-SBF (0.60). As the non-radiative constants are almost identical for both 1-Cbz-SBF and 1-Ph-SBF ${ }^{1}\left(\mathrm{k}_{\mathrm{nr}}=7.5 \times 10^{7} \mathrm{~s}^{-1}\right.$ and $7.2 \times 10^{7} \mathrm{~s}^{-1}$ respectively), one can conclude that the efficiency of the internal conversion processes is similar in the two molecules. Therefore, the lower quantum of 1-Cbz-SBF finds its origin in the radiative constant $\mathrm{k}_{\mathrm{r}}$ which is much lower for 1-Cbz-SBF $\left(4.8 \times 10^{7} \mathrm{~s}^{-1}\right)$ compared to that of $\mathbf{1 - P h}-\mathbf{S B F}\left(1.22 \times 10^{8} \mathrm{~s}^{-1}\right)$. The loss of quantum yield of 1-CbzSBF is therefore due to a lower electronic transition moment. From a molecular point of view, this feature can be assigned to the carbazole itself and not to the 1-substituted-SBF scaffold (in other words the substitution pattern) as both SBF and 1-Ph-SBF possesses almost identical $\mathrm{k}_{\mathrm{r}} / \mathrm{k}_{\mathrm{nr}}$.
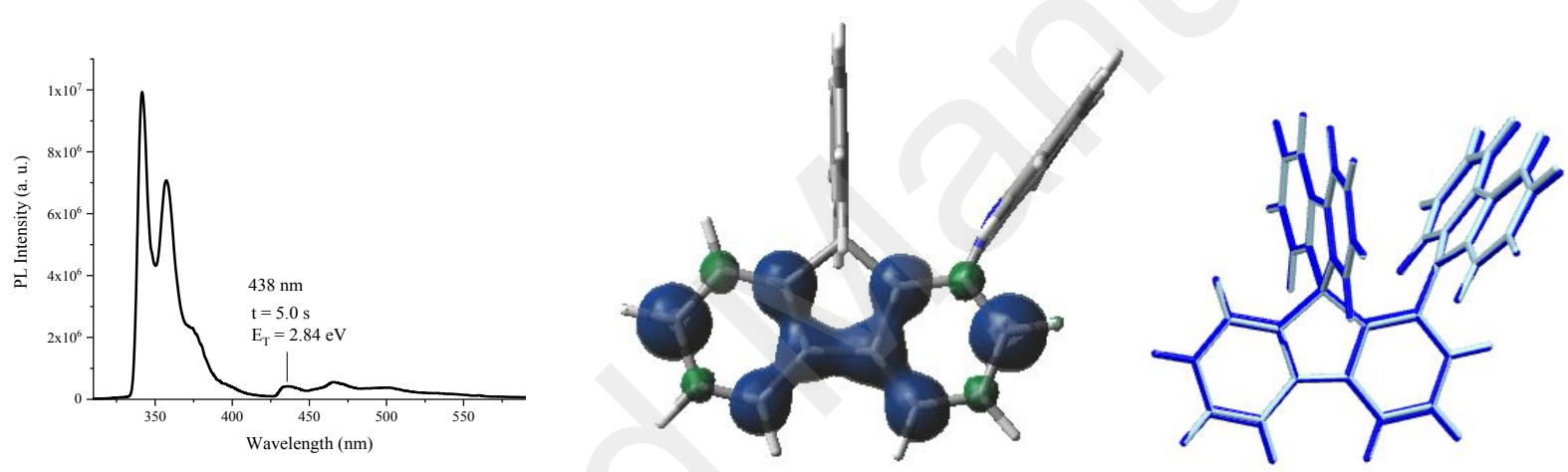

Figure 8. Left: emission spectrum of 1-Cbz-SBF at $77 \mathrm{~K}(2-\mathrm{Me}-\mathrm{THF}, \lambda$ exc $=300 \mathrm{~nm})$. Middle: Spin density of triplet of 1-Cbz-SBF (isovalue= 0.004). Right: Superposition of optimized geometries: $\mathrm{S}_{0}$ (ground state, light blue) and $\mathrm{T}_{1}$ (first triplet excited state, blue)

Finally, at $77 \mathrm{~K}$, the emission spectrum of 1-Cbz-SBF presents a phosphorescence contribution, with a first band centered at $438 \mathrm{~nm}$ followed by two other at 467 and $501 \mathrm{~nm}$ leading to a very high $\mathrm{E}_{\mathrm{T}}$ of $2.84 \mathrm{eV}$ (Figure 8, left). An important feature needs to be stressed out. Indeed, the $\mathrm{E}_{\mathrm{T}}$ of 1-Cbz-SBF is almost identical to that of SBF evaluated at $2.88 \mathrm{eV}^{1}$ (and smaller than that of $\mathbf{C b z}, 3.05 \mathrm{eV}$, measured and determined in identical conditions, Figure S18) highlighting that the pendant substituent has a very weak influence on the $T_{1}$ state being hence different to that of $S_{1}$ (red shift for 1-Cbz-SBF compared to SBF observed both in absorption and in emission, see above). The high $\mathrm{E}_{\mathrm{T}}$ of 1-Cbz-SBF can be explained by the localization of the triplet exciton, which is exclusively spread out on the substituted fluorene with no contribution of the pendant substituent nor its cofacial fluorene (Figure 8, middle). Therefore, the position $\mathrm{C} 1$ which combines an electronic decoupling thanks to the meta linkage and a strong steric hindrance seems to be an ideal position to keep a very high $\mathrm{E}_{\mathrm{T}}$. As the potential applications of $\mathrm{C}$ 1-linked SBFs are in the field of host materials for PhOLEDs, this feature appears promising. In addition, superposition of optimized geometries of the ground state $\mathrm{S}_{0}$ and the first triplet excited state $\mathrm{T}_{1}$ shows that the high rigidity of the $1-\mathrm{SBF}$ scaffold strongly prevents reorganization at the first triplet excited state. As 
for $\mathrm{S}_{0}$, the carbazole-fluorene dihedral angle is very high $\left(90^{\circ}\right)$ at $\mathrm{T}_{1}$ maintaining the $\pi$-conjugation breaking between the two fragments. The $\mathrm{E}_{\mathrm{T}}$ decrease of 1-Cbz-SBF compared to SBF can then be assigned to the cofacial arrangement of the 1-substituted SBF scaffold. Radiative deactivation of the triplet state of 1-Cbz-SBF appears to be very slow under these experimental conditions: $=5.0$ s. This phosphorescence lifetime is slightly lower compare to that of=SBF previously reported, 5.3 $\mathrm{s}^{1}$ (and smaller than that of $\mathbf{C b z}, 7.4 \mathrm{~s}$ ) in accordance with a triplet exciton localized on the fluorene. This highlights that the substitution at $\mathrm{C} 1$ only slightly modifies the phosphorescent lifetime of the $\mathrm{T}_{1}$ state.

\title{
Conclusions
}

The present work reports the synthesis and the study of an example of a new emerging family of spirobifluorene based OSCs, namely 1-substituted spirobifluorenes. Thanks to a structure-property relationship study of 1-carbazolyl-spirobifluorene 1-Cbz-SBF with its building blocks (SBF and $\mathbf{C b z}$ ) and structurally related compounds (N-Ph-Cbz and 1-Ph-SBF) we show that i) there is a complete $\pi$-conjugation breaking between the SBF fragment and the pending substituent at $\mathrm{C} 1$, and ii) there is an intramolecular interaction between the pending substituent at $\mathrm{C} 1$ and the cofacial fluorene (both in solution and in the solid state). The conjugation disruption allows to tune the HOMO energy level of 1-Cbz-SBF. Indeed, the electronic density is mainly spread out on the pending carbazole leading to a strong increase (by ca $0.5 \mathrm{eV}$ ) of the HOMO energy of 1-Cbz-SBF, -5.47 eV, compared to SBF, $-5.96 \mathrm{eV}$. Interestingly, the $\mathrm{E}_{\mathrm{T}}$ of 1-Cbz-SBF is nevertheless maintained at a very high value $(2.84 \mathrm{eV})$ almost identical to that of SBF, $2.88 \mathrm{eV}$. Thus, some electronic properties are driven by the pending carbazole whereas others by the SBF fragment. Furthermore, the strong carbazole/fluorene through space interaction modifies some electronic properties (red shift of the absorption and fluorescence spectra), keeping other almost unaltered (phosphorescence). This $\pi-\pi$ interaction between the $\mathrm{C} 1$ - linked substituent and the cofacial fluorene is therefore an interesting tool to modulate the electronic properties of SBF based materials. In the light of the development of new generations of SBF regioisomers in the last ten years, we believe that 1-substituted SBFs constitute an interesting platform for future organic materials in OE, notably as hosts for PhOLEDs. We are currently working in this direction.

\section{Supporting Information Available}

General Experimental Methods, synthesis and characterization, details on NMR, electrochemical and photophysical studies, X-Ray and theoretical modelling. Copy of NMR spectra.

\begin{abstract}
Abbreviations
PhOLED, phosphorescent organic light-semitting diode; HOMO, highest occupied molecular orbital; LUMO, lowest unoccupied molecular orbital; SBF, 9,9'-spirobifluorene; OSC, organic semi-conductor; OE, Organic Electronics; OLED, organic light emitting diode; $\mathrm{E}_{\mathrm{T}}$, triplet state energy; TMEDA, N,N, $\mathrm{N}^{\prime}, \mathrm{N}^{\prime}$-tetramethylethylenediamine; NMR, nuclear magnetic resonance; $\mathrm{CV}$, cyclic voltammetry; DPV, differential pulse voltammetry; TD-DFT, time-dependent density functional theory; THF, tetrahydrofurane; HFIP, Hexafluoro-2-propanol; TFA, trifluoroacetic acid; SCE, saturated calomel electrode.
\end{abstract}

\section{Conflicts of interest}


There are no conflicts to declare.

\section{Acknowledgments}

The authors would like to thank the CINES (Montpellier $\mathrm{N}^{\circ}$ 2018-A0040805032) for computing time, S. Thiery for preliminary works on 1-carbazolyl-fluorenone and the ANR ( $\left.{ }^{\circ} 14-\mathrm{CE} 05-0024\right)$ for a $\mathrm{PhD}$ grant (LJS) and a post-doctoral position (CQ) and for financial support.

\section{References}

1. Sicard, L.; Quinton, C.; Peltier, J.-D.; Tondelier, D.; Geffroy, B.; Biapo, U.; Métivier, R.; Jeannin, O.; Rault-Berthelot, J.; Poriel, C., Spirobifluorene regioisomerism Chem. Eur. J. 2017, 23, 7719-7723.

2. Poriel, C.; Rault-Berthelot, J., Structure-property relationship of 4-substitutedspirobifluorenes as hosts for phosphorescent organic light emitting diodes: an overview. J. Mater. Chem. C 2017, 5, 3869-3897

3. Saragi, T. P. I.; Spehr, T.; Siebert, A.; Fuhrmann-Lieker, T.; Salbeck, J., Spiro compounds for organic optoelectronics. Chem. Rev. 2007, 107, 1011-1065.

4. Ma, Z.; Sonar, P.; Chen, Z.-K., Recent progress in fluorescent blue materials. Current Organic Chemistry 2010, 18, 2039-2069.

5. Poriel, C.; Rault-Berthelot, J., Dihydroindenofluorene positional isomers. Acc. Chem. Res. 2018, 51, 1818-1830.

6. Quinton, C.; Thiery, S.; Jeannin, O.; Tondelier, D.; Geffroy, B.; Jacques, E.; RaultBerthelot, J.; Poriel, C., Electron-rich 4-substituted spirobifluorenes: Toward a new Family of high triplet energy host materials for high-efficiency green and sky blue phosphorescent OLEDs $A C S$ Appl. Mater. Interfaces. 2017, 9, 6194-6206.

7. Wong, K.-T.; Liao, Y.-L.; Lin, Y.-T.; Su, H.-C.; Wu, C.-C., Spiro-configured bifluorenes: Highly efficient emitter for UV organic light-emitting device and host material for red electrophosphorescence Org. Lett. 2005, 7, 5131-5134.

8. Xing, X.; Xiao, L.; Zheng, L.; Hu, S.; Chen, Z.; Qu, B.; Gong, Q., Spirobifluorene derivative: a pure blue emitter (CIE $\mathrm{y} \approx 0.08)$ with high efficiency and thermal stability J. Mater. Chem. 2012, 22, 15136-15140.

9. Lee, H.; Jung, H.; Kang, S.; Heo, J. H.; Im, S. H.; Park, J., Three-dimensional structures based on the fusion of chrysene and spirobifluorene chromophores for the development of blue OLEDs- high performance in non-doped blue oled. J. Org. Chem 2018, 83, 2640-2646.

10. Zhu, M.; Yang, C., Blue fluorescent emitters: design tactics and applications in organic light-emitting diodes Chem. Soc. Rev. 2013, 42, 4963-4976.

11. Tang, S.; Liu, M.; Lu, P.; Xia, H.; Li, M.; Xie, Z.; Shen, F. Z.; Gu, C.; Wang, H.; Yang, B. et al, A molecular glass for deep-blue organic light-emitting diodes comprising a 9,9'-spirobifluorene core and peripheral carbazole groups Adv. Funct. Mat. 2007, 17, 2869-2877. 
12. Wei, Y.; Chen, C.-T., Doubly ortho-linked cis-4,4'-bis(diarylamino)stilbene/fluorene hybrids as efficient non-doped sky-blue fluorescent materials for optoelectronic applications $J$. Am. Chem. Soc. 2007, 129, 7478-7479.

13. Bian, M.; Wang, Y.; Guo, X.; Lv, F.; Chen, Z.; Duan, L.; Bian, Z.; Liu, Z.; Geng, H.; Xiao, L., Positional isomerism effect of spirobifluorene and terpyridine moieties of "(A)n-D-(A)n" type electron transport materials for long-lived and highly efficient TADF-PhOLEDs. J. Mater. Chem. C 2018, 6, 10276-10283.

14. Shen, J. Y.; Lee, C. Y.; Huang, T.-H.; Lin, J. T.; Tao, Y.-T.; Chen, C.-H.; Tsai, C., High Tg blue emitting materials for electroluminescent devices J. Mater. Chem. 2005, 15, 2455-2463.

15. Li, G.; Wang, S.; Liu, T.; Hao, P.; Liu, Z.; Li, F.; Yang, L.-M.; Zhang, Y.; Li, D.; Yang, S.; et al, Non-fullerene acceptor engineering with three-dimensional thiophene/selenopheneannulated perylene diimides for high performance polymer solar cells. J. Mater. Chem. C 2018, 6, 12601-12607.

16. Li, S.; Liu, W.; Shi, M.; Mai, J.; Lau, T.-K.; Wan, J.; Lu, X.; Li, C.-Z.; Chen, H., A spirobifluorene and diketopyrrolopyrrole moieties based non-fullerene acceptor for efficient and thermally stable polymer solar cells with high open-circuit voltage. Energy Environ. Sci 2016, 9, 604-610.

17. Xia, D.; Gehrig, D.; Guo, X.; Baumgarten, M.; Laquai, F.; Mullen, K., A spiro-bifluorene based 3D electron acceptor with dicyanovinylene substitution for solution-processed non-fullerene organic solar cells. J. Mater. Chem. A 2015, 3, 11086-11092.

18. Yi, J.; Wang, Y.; Luo, Q.; Lin, Y.; Tan, H.; Wang, H.; Ma, C.-Q., A 9,9'-spirobi[9Hfluorene]-cored perylenediimide derivative and its application in organic solar cells as a nonfullerene acceptor. Chem. Commun. 2016, 52, 1649-1652.

19. Wu, X.-F.; Fu, W.-F.; Xu, Z.; Shi, M.; Liu, F.; Chen, H.-Z.; Wan, J.-H.; Russell, T. P., Spiro linkage as an alternative strategy for promising non-fullerene acceptors in organic solar cells. Adv. Funct. Mat. 2015, 25, 5954-5966.

20. Sicard, L. J.; Li, H.-C.; Wang, Q.; Liu, X.-Y.; Jeannin, O.; Rault-Berthelot, J.; Liao, L.-S.; Jiang, Z.-Q.; Poriel, C., C1-Linked spirobifluorene dimers: pure hydrocarbon hosts for highperformance blue phosphorescent OLEDs. Angew. Chem. Int. Ed. 2019, 58, 3848-3853.

21. Jiang, Z.; Yao, H.; Zhang, Z.; Yang, C.; Liu, Z.; Tao, Y.; Qin, J.; Ma, D., Novel oligo-9,9'spirobifluorenes through ortho-linkage as full hydrocarbon host for highly efficient phosphorescent OLEDs Org. Lett. 2009, 11, 2607-2610.

22. Cui, L.-S.; Dong, S.-C.; Liu, Y.; Xu, M.-F.; Li, Q.; Jiang, Z.-Q.; Liao, L.-S., Meta-Linked spirobifluorene/phosphine oxide hybrids as host materials for deep blue phosphorescent organic light-emitting diodes. Org. Electron. 2013, 14, 1924-1930.

23. Thiery, S.; Declairieux, C.; Tondelier, D.; Seo, G.; Geffroy, B.; Jeannin, O.; Métivier, R.; Rault-Berthelot, J.; Poriel, C., 2-Substituted vs 4-substituted-9,9'-spirobifluorene host materials for green and blue phosphorescent OLEDs: a structure-property relationship study Tetrahedron 2014, 70, 6337-6351 
24. Thiery, S.; Tondelier, D.; Declairieux, C.; Geffroy, B.; Jeannin, O.; Métivier, R.; RaultBerthelot, J.; Poriel, C., 4-Pyridyl-9,9'-spirobifluorenes as host materials for green and sky-blue phosphorescent OLEDs J. Phys. Chem. C 2015, 119, 5790-5805

25. Bulut, I.; Chavez, P.; Fall, S.; Mery, S.; Heinrich, B.; Rault-Berthelot, J.; Poriel, C.; Leveque, P.; Leclerc, N., Incorporation of spirobifluorene regioisomers in electron-donating molecular systems for organic solar cells. RSC Adv. 2016, 6, 25952-25959

26. Dong, S.-C.; Gao, C.-H.; Zhang, Z.-H.; Jiang, Z.-Q.; Lee, S.-T.; Liao, L. S., New dibenzofuran/spirobifluorene hybrids as thermally stable host materials for efficient phosphorescent organic light-emitting diodes with low efficiency roll-off Phys. Chem. Chem. Phys. 2012, 14, 14224-14228.

27. Dong, S.-C.; Gao, C.-H.; Yuan, X. D.; Cui, L.-S.; Jiang, Z.-Q.; Lee, S.-T.; Liao, L. S., Novel dibenzothiophene based host materials incorporating spirobifluorene for high-efficiency white phosphorescent organic light-emitting diodes Org. Electron. 2013, 14, 902-908.

28. Lee, K. H.; Kim, S. O.; Yook, K. S.; Jeon, S. O.; Lee, J. Y.; Yoon, S. S., Highly efficient blue light-emitting diodes containing spirofluorene derivatives end-capped with triphenylamine/phenylcarbazole Synth. Met. 2011, 161, 2024-2030.

29. Liu, Y.; Cui, L.-S.; Shi, X.-B.; Li, Q.; Jiang, Z.-Q.; Liao, L.-S., Improved host material for electrophosphorescence by positional engineering of spirobifluorene-carbazole hybrids $J$. Mater. Chem. C 2014, 2, 8736-8744.

30. Ding, L.; Du, S.; Cui, L.-S.; Zhang, F.-H.; Liao, L.-S., Novel spiro-based host materials for application in blue and white phosphorescent organic light-emitting diodes Org. Electron. 2016, 37, 108-114.

31. Kharasch, N.; Bruice, T. C., Derivatives of sulfenic acids. V. 1-fluorenone sulfur compounds J. Am. Chem. Soc. 1951, 73, 3240-3244.

32. George, S. R. D.; Scott, L. T.; Harper, J. B., Synthesis of 1-substituted fluorenones. Polycyclic Aromatic Compounds 2016, 36, 697-715.

33. Chen, X.-Y.; Ozturk, S.; Sorensen, E. J., Synthesis of fluorenones from benzaldehydes and aryl iodides: Dual C-H functionalizations using a transient directing group. Org. Lett. 2017, 19, 1140-1143.

34. Hedidi, M.; Erb, W.; Lassagne, F.; Halauko, Y. S.; Ivashkevich, O. A.; Matulis, V. E.; Roisnel, T.; Bentabed-Ababsa, G.; Mongin, F., Functionalization of pyridyl ketones using deprotolithiation-in situ zincation. RSC Advances 2016, 6, 63185-63189.

35. Romain, M.; Tondelier, D.; Jeannin, O.; Geffroy, B.; Rault-Berthelot, J.; Poriel, C., D Properties modulation of organic semi-conductors based on a donor-spiro-acceptor (D-spiro-A) molecular design: New host materials for efficient sky-blue PhOLEDs J. Mater. Chem. C 2015, 3, 97010-97014.

36. Poriel, C.; Cocherel, N.; Rault-Berthelot, J.; Vignau, L.; Jeannin, O., Incorporation of spiroxanthene units in blue-emitting oligophenylene frameworks: A new molecular design for OLED applications. Chem. Eur. J. 2011, 17, 12631-12645.

37. Thiery, S.; Tondelier, D.; Geffroy, B.; Jeannin, O.; Rault-Berthelot, J.; Poriel, C., Modulation of the physicochemical properties of donor-spiro-acceptor derivatives through donor 
unit planarisation: Phenylacridine versus indoloacridine-new hosts for green and blue phosphorescent organic light-emitting diodes (PhOLEDs) Chem. Eur. J. 2016, 22, 10136-10149.

38. Thirion, D.; Poriel, C.; Métivier, R.; Rault-Berthelot, J.; Barrière, F.; Jeannin, O., Violetto-blue tunable emission of aryl-substituted dispirofluorene-indenofluorene isomers by conformationally-controllable intramolecular excimer formation. Chem. Eur. J. 2011, 17, 1027210287.

39. Rathore, R.; Abdelwahed, S. H.; Guzei, I. A., Synthesis, structure, and evaluation of the effect of multiple stacking on the electron-donor properties of $\pi$-stacked polyfluorenes $\mathrm{J}$. $\mathrm{Am}$. Chem. Soc. 2003, 125, 8712-8719.

40. Nakano, T.; Yade, T., Synthesis, structure, and photophysical and electrochemical properties of a $\pi$-stacked polymer J. Am. Chem. Soc. 2003, 125, 15474-15484.

41. Thirion, D.; Poriel, C.; Barrière, F.; Métivier, R.; Jeannin, O.; Rault-Berthelot, J., Tuning the optical properties of aryl-substituted dispirofluorene-indenofluorene isomers through intramolecular excimer formation. Org. Lett. 2009, 11, 4794-4797.

42. Wang, W.-L.; Xu, J.; Sun, Z.; Zhang, X.; Lu, Y.; Lai, Y.-H., Effect of transannular $\pi-\pi$ interaction on emission spectral shift and fluorescence quenching in dithia[3.3]paracyclophane-fluorene copolymers Macromolecules 2006, 39, 7277-7285.

43. Cornelis, D.; Franz, E.; Asselberghs, I.; Clays, K.; Verbiest, T.; Koeckelberghs, G., Terchromophoric interactions in chiral X-type $\pi$-conjugated oligomers: A linear and nonlinear optical study J. Am. Chem. Soc. 2011, 133, 1317-1322.

44. Nandy, R.; Subramoni, M.; Varghese, B.; Sankararaman, S., Intramolecular $\pi$-stacking interaction in a rigid molecular hinge substituted with 1-(pyrenylethynyl) units J. Org. Chem. 2007, 72, 938-944.

45. Poriel, C.; Rault-Berthelot, J.; Thirion, D.; Barrière, F.; Vignau, L., Blue emitting $3 \pi-$ 2 Spiro terfluorene-indenofluorene isomers: A structure-properties relationship study. Chem. Eur. J. 2011, 17, 14031-14046.

46. Bondi, A., van der Waals volumes and radii J. Phys. Chem. 1964, 68, 441-451.

47. Yang, X.-J.; Drepper, F.; Wu, B.; Sun, W.-H.; Haehnel, W.; Janiak, C., From model compounds to protein binding: syntheses, characterizations and fluorescence studies of $\left[\mathrm{RuII}(\right.$ bipy)(terpy)L $] 2+$ complexes (bipy $=2,2^{\prime}$-bipyridine; terpy $=2,2^{\prime}: 6^{\prime}, 2^{\prime \prime}$-terpyridine; $\mathrm{L}=$ imidazole, pyrazole and derivatives, cytochrome c) Dalton Trans. 2005, 256-267.

48. Craven, E.; Zhang, C.; Janiak, C.; Rheinwald, G.; Lang, H., Dimethyl-2, 2'-bipyridine)(IDA)copper(II) and structural comparison with aqua(IDA)(1, 10-phenanthroline)copper(II) (IDA = iminodiacetato) Anorg. Allg. Chem 2003, 629, 2282-2290.

49. Janiak, C., A critical account on $\pi-\pi$ stacking in metal complexes with aromatic nitrogencontaining ligands J. Chem. Soc., Dalton Trans. 2000, 3885-3896.

50. Banerjee, S.; Ghosh, A.; Wu, B.; Lassahn, P.-G.; Janiak, C. Polymethylene spacer regulated structural divergence in cadmium complexes: Unusual trigonal prismatic and severely distorted octahedral coordination Polyhedron 2005, 24, 593-599. 
51. Ambrose, J. F.; Nelson, R. F., Anodic oxidation pathways of carbazoles I . carbazole and N-substituted derivatives J. Electrochem. Soc. 1968, 1159-1164.

52. Tang, G.-M.; Chi, R.-H.; Wan, W.-Z.; Chen, Z.-Q.; Yan, T.-X.; Dong, Y.-P.; Wang, Y.T.; Cui, Y.-Z., Tunable photoluminescent materials based on two phenylcarbazole-based dimers through the substituent groups. J. Lumin. 2017, 185, 1-9.

53. Chebny, V. J.; Shukla, R.; Lindeman, S. V.; Rathore, R., Molecular Actuator: RedoxControlled Clam-Like Motion in a Bichromophoric Electron Donor Org. Lett. 2009, 11, 19391942.

54. Qi, H.; Chang, J.; Abdelwahed, S. H.; Thakur, K.; Rathore, R.; Bard, A. J., Electrochemistry and electrogenerated chemiluminescence of $\pi$-stacked poly(fluorenemethylene) oligomers. Multiple, interacting electron transfers. J. Am. Chem. Soc. 2012, 134, 16265-16274.

55. Poriel, C.; Rault-Berthelot, J.; Thirion, D., Modulation of the electronic properties of $3 \pi-$ 2spiro compounds derived from bridged oligophenylenes: A structure-property relationship. $J$. Org. Chem. 2013, 73, 886-898.

56. Rault-Berthelot, J.; Granger, M. M.; Mattiello, L., Anodic oxidation of 9,9'-spirobifluorene in $\mathrm{CH}_{2} \mathrm{Cl}_{2}+0.2 \mathrm{M} \mathrm{Bu}_{4} \mathrm{NBF}_{4}$. Electrochemical behaviour of the derived oxidation product. Synth. Met. 1998, 97, 211-215.

57. Poriel, C.; Ferrand, Y.; Le Maux, P.; Rault-Berthelot, J.; Simonneaux, G., Organic crosslinked electropolymers as supported oxidation catalysts: Poly((tetrakis $\left(9,9^{6}\right.$ spirobifluorenyl)porphyrin)manganese) films Inorg. Chem. 2004, 43, 5086-5095.

58. Ferrand, Y.; Poriel, C.; Le Maux, P.; Rault-Berthelot, J.; Simonneaux, G., Asymmetric heterogeneous carbene transfer catalyzed by optically active ruthenium spirobifluorenylporphyrin polymers. Tetrahedron Asymmetry 2005, 16, 1463-1472.

59. Poriel, C.; Ferrand, Y.; Le Maux, P.; Paul-Roth, C.; Simonneaux, G.; Rault-Berthelot, J., Anodic oxidation and physicochemical properties of various porphyrin-fluorenes or spirobifluorenes: Synthesis of new polymers for heterogeneous catalytic reactions J. Electroanal. Chem. 2005, 583, 92-103.

60. Poriel, C.; Ferrand, Y.; Juillard, S.; Le Maux, P.; Simonneaux, G., Synthesis and stereochemical studies of di and tetra 9,9'-spirobifluorene porphyrins: New building blocks for catalytic material Tetrahedron 2004, 60, 145-158.

61. Geuenich, D.; Hess, K.; Köhler, F.; Herges, R., Anisotropy of the induced current density (ACID), a general method to quantify and visualize electronic delocalization Chem. Rev. 2005, $105,3758-3772$.

62. Simmons, H. E.; Fukunaga, T., Spiroconjugaison. J. Am. Chem. Soc. 1967, 89, 5208.

63. Hintschich, S. I.; Rothe, C.; King, S. M.; Clark, S. J.; Monkman, A. P., The complex excited-state behavior of a polyspirobifluorene derivative: The role of spiroconjugation and mixed charge transfer character on excited-state stabilization and radiative lifetime J. Phys. Chem. B 2008, 112, 16300-16306.

64. Lukes, V.; Solc, R.; Milota, F.; Sperling, J.; Kauffmann, H. F., Theoretical investigation of the structure and the electron-vibrational dynamics of 9,9'-spirobifluorene Chem. Phys. 2008, 349, 226-233. 
65. Kowada, T.; Kuwabara, T.; Ohe, K., Synthesis, structures, and optical properties of heteroarene-fused dispiro compounds J. Org. Chem. 2010, 75, 906-913.

66. Pan, H.; Fu, G.-L.; Zhao, Y.-H.; Zhao, C.-H., Through-space charge-transfer emitting biphenyls containing a boryl and an amino group at the $o, o^{\prime}$-positions Org. Lett. 2011, 13, 48304833.

67. Romain, M.; Tondelier, D.; Geffroy, B.; Jeannin, O.; Jacques, E.; Rault-Berthelot, J.; Poriel, C., Donor/Acceptor dihydroindeno[1,2-a]fluorene and dihydroindeno[2,1-b]fluorene: Towards new families of organic semiconductors. Chem. Eur. J. 2015, 21, 9426-9439. 


\section{TOC GRAPHIC}

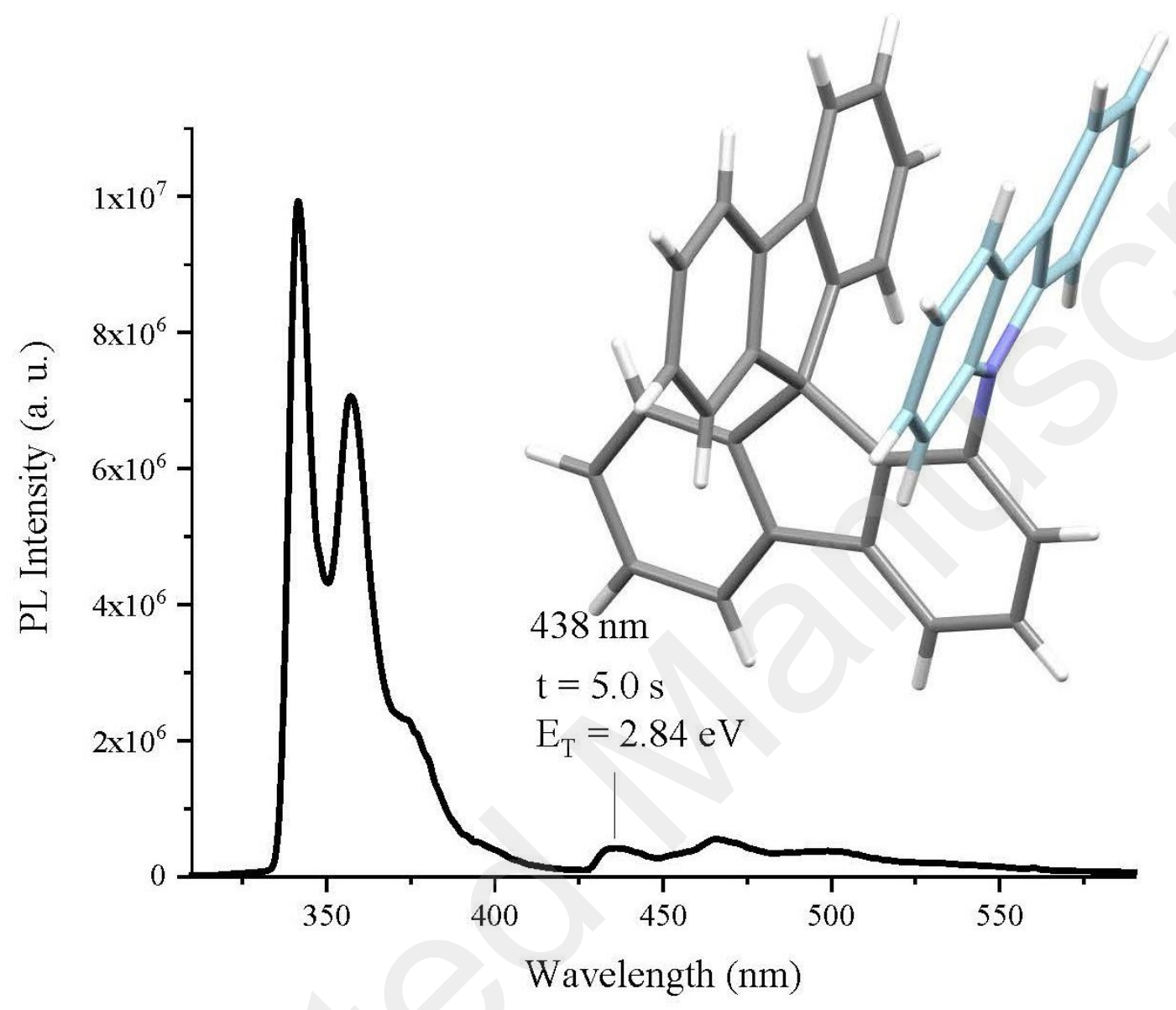

ACS Paragon Plus Environment 